\title{
Mapping the protonation states of the histidine brace in an AA10 lytic polysaccharide monooxygenase using CW- EPR spectroscopy and DFT calculations $\dagger$
}

\author{
Peter J. Lindley, (iD Alison Parkin, (iD Gideon J. Davies (iD \\ and Paul $\mathrm{H}$. Walton iD *
}

\begin{abstract}
Received 13th October 2021, Accepted 4th November 2021
DOI: $10.1039 / \mathrm{d} 1 \mathrm{fd} 00068 \mathrm{c}$
\end{abstract}

The active site of the polysaccharide-degrading lytic polysaccharide monooxygenase (LPMO) enzyme features a single copper ion coordinated by a histidine brace. The primary coordination sphere of the copper contains several ligating atoms which are bonded to ionisable protons (e.g. $\mathrm{OH}_{2}, \mathrm{NH}_{2}$ ), the $\mathrm{p} K_{\mathrm{a}} \mathrm{s}$ of which are unknown. Using a combination of CW-EPR X-band spectroscopy over a range of $\mathrm{pH}$ values and DFT calculations, we show that the active site of a chitin-active AA10 LPMO can exist in three different protonation states $\left(\mathrm{p} K_{\mathrm{a} 1}=8.7, \mathrm{p} K_{\mathrm{a} 2} \sim 11.5\right)$, representing the ionisation of the coordinating groups. The middle $\mathrm{pH}$ species (fully formed at $\mathrm{pH} \sim 10.5$ ) is proposed to be $\mathrm{Cu}(\mathrm{II})(\mathrm{His})_{2}(\mathrm{OH})_{2}\left(\mathrm{~N}_{2} \mathrm{O}_{2}\right.$ coordination) with a decoordinated $\mathrm{R}-\mathrm{NH}_{3}{ }^{+}$group at the amino terminus. This species also sees a rotation of the SOMO equatorial plane from the canonical histidine brace plane, whereby the nominal $\mathrm{Cu} d\left(x^{2}-y^{2}\right)$-orbital has rotated some $45^{\circ}$ along the His- $\mathrm{Cu}(\|)-\mathrm{His}$ axis, driven by the elongation and decoordination of the amino group. The highest $\mathrm{pH}$ species $(>12)$ is proposed to exist as a $\mathrm{Cu}(\|)$-azanide, in which the $\mathrm{NH}_{2}$ of the amino terminus has been deprotonated. The high $\mathrm{pH}$ means that this species is unlikely to be biologically relevant in the catalytic cycle of AA10 LPMOs.

\section{Introduction}

Lytic polysaccharide monooxygenases (LPMOs) are copper-containing enzymes which catalyse the oxidative cleavage of glycosidic bonds within polysaccharides. ${ }^{\mathbf{1 - 3}}$ The active site of LPMOs has been shown by crystallography to contain a single copper ion coordinated in a T-shaped configuration by a 'histidine brace', which consists of an N-terminal histidine chelating to the copper via its $\mathrm{NH}_{2}$ and $\pi-\mathrm{N}$ imidazole atoms, along with the $\tau-\mathrm{N}$ atom of a further histidine. ${ }^{4}$

Department of Chemistry, University of York, Heslington, York, YO10 5DD, UK. E-mail: paul.walton@york.ac. $u k$

$\dagger$ Electronic supplementary information (ESI) available. See DOI: 10.1039/d1fd00068c 
In the copper(II) resting state, the structures further show that one or two exogenous ligands, usually water or hydroxide, occupy the remaining copper coordination sites.

LPMOs are divided into auxiliary activity (AA) families in the Carbohydrate Active enZyme (CAZy) database (www.cazy.org) based on sequence similarity, where so far eight distinct classes have been characterised (AA9-11, AA1317) ${ }^{\mathbf{1 , 2 , 5 - 1 0}}$ The number of exogenous ligands is partly dependent on the genomic class of the LPMO. For instance, structures of AA9-classified enzymes exhibit a single water/hydroxide to give a planar $\mathrm{N}_{3} \mathrm{O}$ coordination geometry around the copper, whereas chitin-active AA10-classified enzymes appear to show the copper(II) in a distorted square-pyramidal $\mathrm{N}_{3} \mathrm{O}_{2}$ geometry, where two exogenous water/hydroxide ligands complete the coordination sphere, as depicted in Fig. 1. In both the AA9 and AA10 cases, EPR spectroscopy has established that the SOMO is dominated by the $\mathrm{d}\left(x^{2}-y^{2}\right)$ orbital, requiring the ligand field of the copper to have a large sigma-bonding component in the equatorial plane of the metal ion. In the case of AA9 LPMOs, the coordination geometry of the $\mathrm{Cu}$ is best described as axially elongated, whereas in the case of AA10 LPMOs, EPR spectroscopy has shown $c a .3 \%$ of $\mathrm{d}\left(z^{2}\right)$ mixing into the largely $\mathrm{d}\left(x^{2}-y^{2}\right)$ SOMO, commensurate with a distorted square-pyramidal geometry. ${ }^{\mathbf{1 1 , 1 2}}$

In chitin-active AA10 LPMOs, the large number of ionisable protons of the ligands, which coordinate to the copper ion in the histidine brace $\left(\mathrm{NH}_{2}, 2 \times \mathrm{H}_{2} \mathrm{O}\right)$, opens up the possibility that the copper(II) centre exhibits a range of different protonation states, some of which may be relevant to the enzyme's catalytic cycle. Indeed, this reasoning has extended as far as suggesting that the amino terminus can deprotonate itself to form a copper(II)-azanide bond, the $\sigma$-donating power of which is expected to be high and possibly capable of stabilising a high valent copper species. ${ }^{13}$ Such a species may be a key intermediate in the catalytic cycle which is capable of abstracting a hydrogen atom from the polysaccharide substrate. ${ }^{2,14}$ As such, determining the different degrees of protonation of the active site is germane to any discussion about the catalytic mechanisms of LPMOs.

It is in this context that we aimed to establish the nature of the different protonation states of the active site of an AA10 LPMO from the bacterium Bacillus

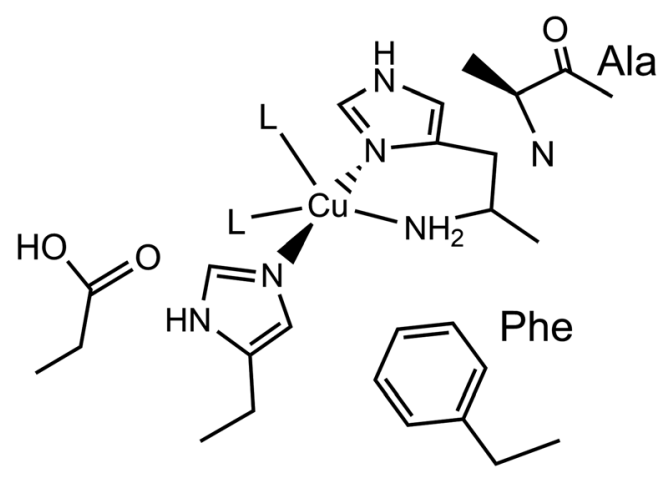

Fig. 1 Active site of a chitin-active AA10 LPMO, depicting the histidine brace exogenous ligands (L) ligating to the $\mathrm{Cu}(\mathrm{II})$ ion, and conserved residues. 
licheniformis, Bl(AA10). ${ }^{15}$ To this end, we employed CW-EPR spectroscopy in conjunction with DFT calculations to show that the active site exists in three distinct protonation states across the $\mathrm{pH}$ range 6.5 to 12.5. We further show that the highest $\mathrm{pH}$ species is most likely to be the copper(II)-azanide species proposed earlier, ${ }^{2,13}$ but that it only exists at $\mathrm{pH}$ outside the usual biological range, and is not a biologically relevant species for the resting state of the enzyme.

\section{Results and discussion}

\section{Preparation and purity of Bacillus licheniformis AA10 LPMO}

Samples of this enzyme were prepared in Escherichia coli (BL21 competent cells) via periplasmic expression, previously reported by Courtade et al. ${ }^{16}$ Crude protein was obtained from the periplasm by osmotic shock and further purified using a $5 \mathrm{~mL}$ HiTrap ${ }^{\circledR}$ DEAE FF anion exchanger, eluting with a $\mathrm{NaCl}$ gradient from 0 $500 \mathrm{mM}$ over 90 column volumes. LPMO-containing fractions were collected and further purified on a Superdex S75 gel filtration column (GE Life Sciences).

The purity of $B l($ AA10) was established by gel electrophoresis, which displayed a clear and single band at $c a .20 \mathrm{kDa}(\mathrm{ESI} \dagger)$. For the subsequent EPR experiments, it was important to determine that all copper in the sample was bound stoichiometrically to the active site of the enzyme. On this basis, a single equivalent of $\mathrm{Cu}$ was added to the enzyme from a solution of $10 \mathrm{mM} \mathrm{CuSO}_{4}$ prior to size exclusion chromatography, from which any uncoordinated metal ions were separated from the purified enzyme.

\section{CW-EPR X-band spectroscopy}

A sample of $B l$ (AA10) (0.4 mM) was prepared in a mixed buffer system of MES, CHES, HEPES and CAPS, each at $5 \mathrm{mM}$. These buffers were chosen for their known poor-coordination properties toward metal ions and, when used synchronously, buffer a wide range of $\mathrm{pHs}$. The $\mathrm{pH}$ of the solution was adjusted up and down by the addition of dilute solutions of $\mathrm{NaOH}$ and $\mathrm{H}_{2} \mathrm{SO}_{4}$, respectively. The $\mathrm{pH}$ of the resulting solution at room temperature was determined using a calibrated Fisherbrand ${ }^{\mathrm{TM}}$ Accumet ${ }^{\mathrm{TM}}$ AE150 Benchtop pH Meter, from which 12 samples from $\mathrm{pH} 6.5$ to 12.5 were prepared in $0.5 \mathrm{pH}$ unit steps. To verify that the $\mathrm{pH}$ extremes did not denature the protein, EPR spectra were collected on samples starting at $\mathrm{pH} 6.5$ and then raising to $\mathrm{pH}$ 12.5, and then recollected on the same sample at a lower $\mathrm{pH}$, indeed restoring the previous species.

At each $\mathrm{pH}$, the sample was rapidly $(<2 \mathrm{~s})$ cooled $^{17}$ to $150 \mathrm{~K}$ and its CW-EPR X band spectrum collected. $\$$ The trend of the EPR spectra shows a qualitative change across the $\mathrm{pH}$ range, in which it is evident that all species have a spectral envelope which is consistent with a predominantly $\mathrm{d}\left(x^{2}-y^{2}\right)$ SOMO, showing that the $\mathrm{Cu}(\mathrm{II})$ ion at all pHs has a ligand field dominated by sigma donation in its equatorial plane (Fig. 2). Spin quantification by double integration of the spectra

\footnotetext{
\$ Continuous wave (CW) X-band EPR spectra were obtained using a $100 \mu \mathrm{L}$ frozen solution of BlAA10 at a concentration of $0.4 \mathrm{mM}$. Data collection was carried out on a Bruker micro EMX spectrometer using a microwave frequency of $c a .9 .3 \mathrm{GHz}$, modulation amplitude of $4 \mathrm{G}$, modulation frequency of $100 \mathrm{kHz}$ and microwave power of $10.02 \mathrm{~mW}$. Spectra were intensity averaged over three scans and simulated using the EasySpin 5.2.28 (ref. 27) open-source toolbox implemented by MATLAB R2020a software on a desktop PC. Raw EPR data are available at DOI: 10.15124/7a485d50-ea4e-4cd1-8fc2-650057c076af.
} 

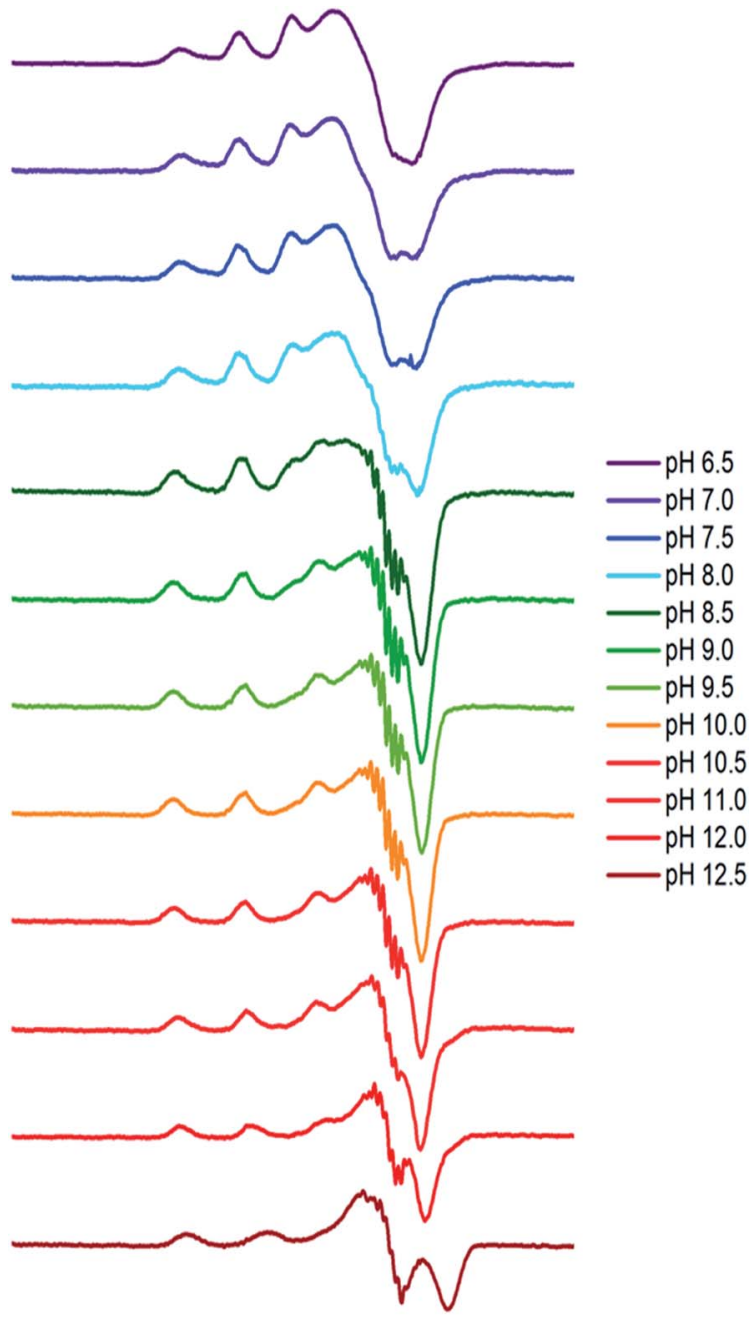

12.5

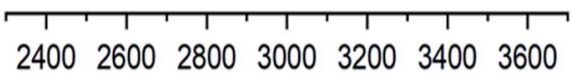

Field / G

Fig. 2 Frozen solution X-band EPR spectra (150 K) of Bl(AA10) $(0.4 \mathrm{mM})$ in a mixed buffer of MES, CHES, HEPES and CAPS (5 mM each) between $\mathrm{pH} 6.5$ and 12.5 .

also shows that there are no redox processes that occur at the active site across the $\mathrm{pH}$ range (ESI $\dagger$ ).

\section{Analysis of EPR spectra and distribution of $\mathrm{pH}$ dependent species}

Between pHs 6.5 and 8.0, a single species is seen to dominate the spectrum, as evidenced by a single set of $\mathrm{Cu}$ hyperfine split peaks at low field $\left(g_{3}=2.260, A_{3}=\right.$ $445 \mathrm{MHz}$ ). Increasing the $\mathrm{pH}$ leads to the formation of a new set of peaks in the low field region $\left(g_{3}=2.233, A_{3}=554 \mathrm{MHz}\right)$ along with distinctive superhyperfine 
coupling around $g=2.07$, commensurate with the formation of a second distinct species, the concentration of which is maximised at $\mathrm{pH}$ 10.5. A further increase in $\mathrm{pH}$ to 12.5 sees the formation of a further set of peaks in the low field region $\left(g_{3}=\right.$ $2.180, A_{3}=614 \mathrm{MHz}$ ), consistent with the formation of a third distinct species. This final species is not fully formed at $\mathrm{pH} 12.5$ but is dominant at that $\mathrm{pH}$. The total number of species across the $\mathrm{pH}$ range was assessed using singular value decomposition analysis of the collected spectra (ESI $\dagger$ ). From this analysis, three principal components emerged, corroborating the qualitative assessment of the pH dependence of the EPR spectra.

On the basis of the three components (species 1, 2 and 3), we sought to deconvolute the series of spectra. Given the clear separation between the different species across the $\mathrm{pH}$ range, it was assumed that the spectrum at $\mathrm{pH} 6.5$ represented $100 \%$ of a single complex. Indeed, it was possible to simulate (with EasySpin) the lowest $\mathrm{pH}$ species (pH 6.5) with a single set of spin-Hamiltonian parameters (Fig. 3a and Table 1). The same was also true of the spectra collected at $\mathrm{pH} 10.5$ and 12.5 (Fig. $3 \mathrm{~b}$ and c, respectively, Table 1). In performing the simulation of species 3, we noted the appearance of a significant 'overshoot' feature which appears at high field in the species at pH 12.5. Such a feature has in the past been confused with an anomalously low $g_{1}$ value. $^{18}$

Once spin Hamiltonian parameters of each species were obtained, it was possible to simulate the mixed species spectra (pHs 7 to 9.5 and >10.5) to determine the species distributions at each $\mathrm{pH}$, from which the $\mathrm{p} K_{\mathrm{a}} \mathrm{s}$ of species 1 (low $\mathrm{pH}$ ) and species 2 (middle $\mathrm{pH}$ ), and the stoichiometry of protons for each ionisation, were determined using standard methods (ESI $\dagger$ ). The deprotonation of species 1 to 2 occurs with a $\mathrm{p} K_{\mathrm{a}}$ of 8.7 and is a single proton step. The deprotonation of species 2 to 3 occurs with a $\mathrm{p} K_{\mathrm{a}}$ of $\sim 11.5$ and is also a single proton step.

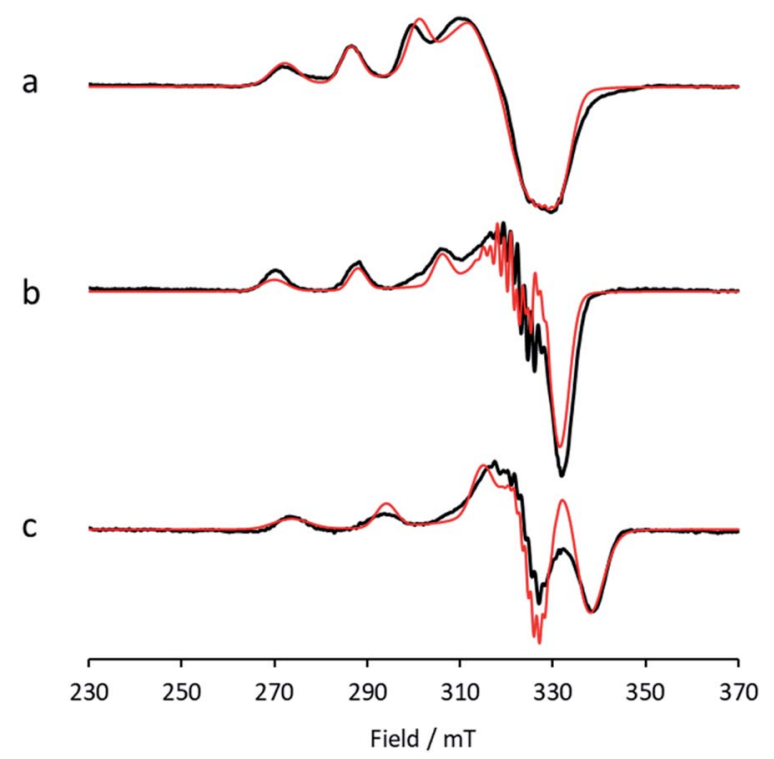

Fig. 3 X-band EPR (a) low pH species 1, with simulation (red), (b) intermediate pH species 2 , with simulation (red), (c) high $\mathrm{pH}$ species 3 , with simulation (red). 
Table 1 Spin Hamiltonian parameters of the $\mathrm{pH}$ dependent species. It is assumed that the $A_{3}$ value is negative in sign, although this is not determined experimentally

\begin{tabular}{|c|c|c|c|c|c|c|c|}
\hline \multirow[b]{2}{*}{ Species } & \multicolumn{3}{|c|}{$g$ values } & \multicolumn{3}{|c|}{$\begin{array}{l}\text { Hyperfine coupling } \\
\text { constants/MHz }\end{array}$} & \multirow[b]{2}{*}{$b^{2} / \%$} \\
\hline & $g_{1}$ & $g_{2}$ & $g_{3}$ & $\left|A_{1}\right|$ & $\left|A_{2}\right|$ & $A_{3}$ & \\
\hline 1 & 2.030 & 2.125 & 2.260 & 60 & 90 & -445 & 3.6 \\
\hline 2 & 2.044 & 2.069 & 2.233 & 60 & 76 & -554 & 0.8 \\
\hline 3 & 2.038 & 2.062 & 2.180 & 70 & 90 & -614 & 0.9 \\
\hline
\end{tabular}

\section{Ligand field analyses of spin Hamiltonian parameters}

The collected spin Hamiltonian parameters of the three species are shown in Table 1. In all cases, the $g$ values follow the pattern of $g_{1}<g_{2} \ll g_{3}$, confirming a SOMO with a high $\mathrm{d}\left(x^{2}-y^{2}\right)$ character. Some $\mathrm{d}\left(z^{2}\right)$ mixing is evident for all species from the differences in the values of $g_{1}$ and $g_{2}$. The degree of mixing, $b^{2}$, can be calculated from the standard perturbative EPR formulae as described by Hitchman et al.,$^{19}$ which give the molecular orbital coefficients, $a$ and $b$, for the SOMO defined in eqn (1) (Table 1).

$$
\psi(\mathrm{SOMO})=a \psi\left(x^{2}-y^{2}\right)+b \psi\left(z^{2}\right)
$$

This mixing is low for species 2 and 3, revealing that the ligand field around the $\mathrm{Cu}$ in each of these is close to axial four-fold symmetry (note that this does not necessarily translate into a four-fold axial symmetry of the identity of the coordinating atoms, as different coordinating atoms may have similar ligand field parameters). For species 1 , more mixing is evident $\left(b^{2}=3.6 \%\right)$, which is in-line with previous EPR studies on AA10 LPMOs ${ }^{11}$ and the subsequent structures of these enzymes, which exhibit a distorted square pyramidal geometry around the copper ion (Fig. 1), where the exogenous ligands are two water/hydroxide molecules, one of which forms a $\mathrm{Cu}-\mathrm{O}$ bond of $c a$. 1.9 A, and the other a more distant bond of $2.2 \mathrm{A.}^{20}$

Taking the value of $g_{3}$ as a measure of the relative ligand field strengths in the equatorial plane of the copper, it is evident that this ligand field increases significantly moving from species 1 to 2 to 3 , and-moreover, from the values of $\mathrm{d}\left(z^{2}\right)$ mixing - that the ligand field in species 2 and 3 is relatively evenly distributed amongst the ligating atoms of the equatorial plane, suggestive of a near fourfold symmetric planar arrangement of the equatorial ligand field. Indeed, corroborating such a ligand field, the increase in $A_{3}$ value from species 1 to 2 is also known to be associated with a change in the Fermi coupling as the coordination number of the copper drops from five to four. ${ }^{15}$ Without access to the $\mathrm{d}-$ $\mathrm{d}$ electronic transition energies, it is not possible to be more precise about the nature of the ligand field; nevertheless the trend in increasing ligand field around the equatorial plane is evident from the relative spin-Hamiltonian parameters.

Further information about the ligand field in species 2 can be obtained from the clearly delineated $\mathrm{Cu}-\mathrm{N}$ superhyperfine coupling (Fig. 3b). This coupling could be accurately simulated with the inclusion of two nitrogen atoms $\left({ }^{14} \mathrm{~N}, I=1\right)$ in the spin Hamiltonian, in which each $\mathrm{N}$ atom couples to the copper with 
a principal coupling value of $40 \mathrm{MHz}$. This value is similar to those already known for the $\mathrm{Cu}$-His coupling constants seen in other LPMOs. ${ }^{17,21}$ The simulation of species 2 could be adequately performed with the inclusion of two $\mathrm{N}$ nuclei, incommensurate with the expected $\mathrm{N}_{3}$ coordination of the histidine brace. Additionally, the $g_{3}$ and $A_{3}$ values of species 2 place it squarely within those expected for a $\mathrm{CuN}_{2} \mathrm{O}_{2}$ coordination geometry on a canonical Peisach-Blumberg plot. $^{22}$

In assigning a putative structure to species 2, it is informative to consider previous EPR studies on the substrate-bound state of chitin-active AA10 enzymes. These species have been well characterised as having a planar $\mathrm{CuN}_{3} \mathrm{O}$ coordination geometry with a $g_{z}$ value of 2.205 and an $A_{z}$ value of $\sim 620 \mathrm{MHz} .^{15,23}$ On this basis, a similar axial $\mathrm{CuN}_{3} \mathrm{O}$ (sq. pl) ligand field is unlikely for species 2, given the discrepancies in the $g_{z}$ and $A_{z}$ values. This difference in the spin Hamiltonian parameters necessitates an alternative ligand field assignment for species 2 . Thus, taking together the $\mathrm{Cu}$ spin Hamiltonian values and superhyperfine couplings, a more likely scenario is one in which the $\mathrm{NH}_{2}$ group of the histidine brace is decoordinated from the copper (see DFT calculations below) and the coordination sphere around the $\mathrm{Cu}$ is made up of two histidines and two water/ hydroxide ligands (see below for further discussion).

The spin Hamiltonian parameters for species 3 are distinct from those of other known LPMOs, which is particularly evident in the value of $g_{3}(2.18)$, which is lower than all known values, including the situation in which a chloride ion has entered the coordination sphere of the copper $\left(g_{3}=2.23\right)$. Given the low value, we are directed towards the proposal that the ligand field around the copper in species 3 is one that is highly $\sigma$-donating, causing a large separation in the $\mathrm{d}\left(x^{2}-\right.$ $\left.y^{2}\right)$ and $\mathrm{d}(x y)$ orbital energies. Such a strong $\sigma$ donation might be expected of a $\mathrm{Cu}$-azanide interaction, which would arise from the recoordination of the $-\mathrm{NH}_{3}{ }^{+}$amino terminus in species 2 which had been doubly deprotonated to give a $-\mathrm{NH}^{-}$ligating group. Commensurate with this proposal is the simulation of the superhyperfine coupling in species 3 , which could only be satisfactorily achieved with the inclusion of three nitrogen atoms in the spin Hamiltonian with principal coupling constants of 35, 35 and $33 \mathrm{MHz}$ (see DFT calculations below).

From the overall ligand field analysis, a hypothesis emerges for the nature of species 1, 2 and 3 and the pH-dependent ionisation processes between them. The hypothesis is depicted in Fig. 4, in which it is shown that species 2 forms via the deprotonation of a coordinating water molecule, followed by the decoordination and subsequent protonation of the $-\mathrm{NH}_{2}$ group, driven by an internal proton

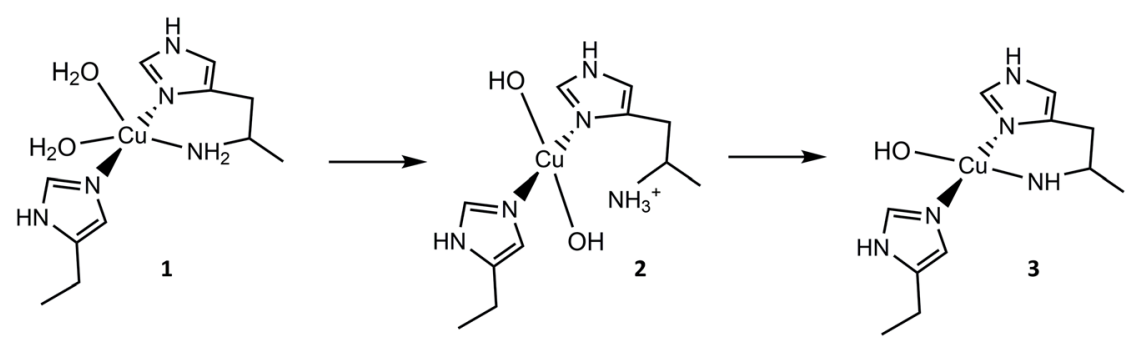

Fig. 4 Hypothetical protonation states and coordination geometries of species 1, 2 and 3. 
transfer process from one of two coordinating water molecules in species 1 . The formation of species 3 from species 2 , on the other hand, sees the reverse proton transfer from the decoordinated $-\mathrm{NH}_{3}{ }^{+}$to a coordinated hydroxide with the loss of the resulting water molecule, and the subsequent deprotonation of an $\mathrm{N}-\mathrm{H}$ proton from the $-\mathrm{NH}_{2}$ and recoordination to the metal as an azanide. In support of such an assignment, the formation of species 3 was accompanied by an unusual colour change from colourless to pale pink (ESI $\dagger$ ) due to the formation of a semi-intense absorption band $\left(\varepsilon \approx 2500 \mathrm{M}^{-1} \mathrm{~cm}^{-1}\right)$ centred at $520 \mathrm{~nm}$. The intensity of this band is in keeping with that of a charge transfer transition - likely arising from a ligand to metal charge transfer (LMCT) from the proposed azanide $\left(-\mathrm{NH}^{-}\right)$group to the copper (see TD-DFT calculations, ESI $\dagger$ ). Thus, the proposed ligand field changes depicted in Fig. 4 are revealed by the differences in the spin Hamiltonian parameters across the species, in which $g_{z}$ decreases and $A_{z}$ increases (going from species 1 to 3 ), commensurate with an increasing equatorial ligand field.

\section{DFT calculations}

Building on the hypothesis depicted in Fig. 4, density functional theory geometry optimisations (uBP86) and EPR calculations (uB3LYP with 38\% HF exchange) were performed on the proposed species 1, 2 and 3 .

In the absence of a high-resolution crystal structure for the Bacillus licheniformis AA10, crystallographic coordinates of the spectroscopically similar enzyme, Bacillus amyloliquefaciens AA10 (PDB 5IJU), ${ }^{20}$ were used as the basis for these calculations, in keeping with the experiments of Courtade et al. ${ }^{15}$ Importantly in this regard, the structure of BaAA10 is one of the few LPMO structures in which the copper ion has not been photoreduced from $\mathrm{Cu}$ (II) to $\mathrm{Cu}(\mathrm{I})$ during the $\mathrm{X}$ ray experiment. ${ }^{24}$ Accordingly, key residues from the crystallographic coordinates were used for the basis of the calculations for species 1, retaining the primary coordination sphere and supporting residues (full information and coordinates are given in the ESI $\dagger$ ). Following standard practice, the spatial coordinates of certain atoms at the periphery of the model were kept fixed throughout the calculation to prevent the unfettered movement of residues. These atoms are depicted in Fig. S7 (ESI $\dagger$ ) and were selected on the basis of earlier DFT studies on a closely related LPMO. ${ }^{15}$

For species 1 , the geometry was initially modelled with the inclusion of two ligating water molecules with bond distances based on the positioning of the oxygen atoms in the crystal structure. Notably in this regard, the water situated beneath the histidine brace plane is expected to participate in strong hydrogen bonding with a nearby aspartate residue (glutamate in BaAA10), the potential of which can affect the protonation state and ligating properties of the water molecule. Indeed, upon optimisation, despite the fact that Glu and Asp residues are expected to be deprotonated across the studied $\mathrm{pH}$ range owing to the low $\mathrm{p} K_{\mathrm{a}} \mathrm{s}$ of their carboxylate groups $\left(\mathrm{p} K_{\mathrm{a}}=2-4.5\right),{ }^{25}$ one of the protons bound to the water molecule migrated to the neighbouring carboxylate group (Fig. 5) to give a mixed hydroxide/water coordination at the $\mathrm{Cu}$. Confidence in this structural assignment comes from the resulting geometry of the optimised structure, which is a close match to the crystal structure coordinates. Thus, for species 1 , the coordination sphere of the $\mathrm{Cu}$ is best described as a distorted square-pyramid, where water and hydroxide act as exogenous ligands. 


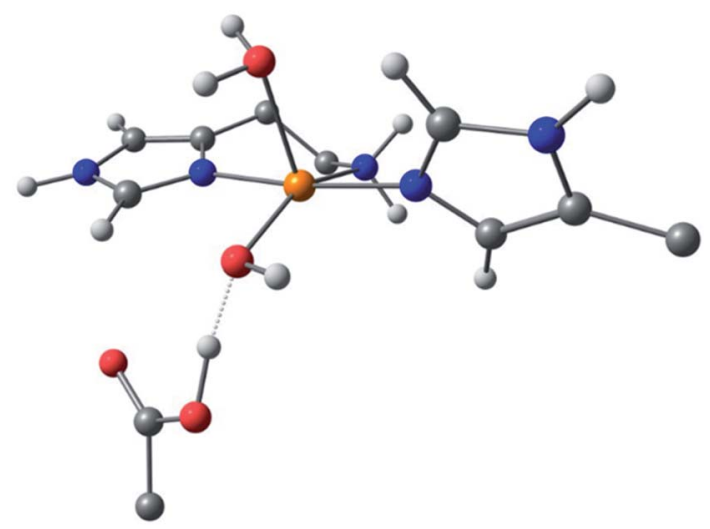

Fig. 5 DFT model of species 1 (truncated for clarity) showing the distorted squarepyramidal geometry and hydroxide/water coordination of the exogenous ligands.

While a good match was found between the optimised and experimental structures, the match between the calculated and experimental EPR parameters (Table 2 ) was only moderate (e.g. calculated $g_{3}=2.216$, experimental $g_{3}=2.26$ ). Moreover, the calculated Cu hyperfine values, $A_{1}$ and $A_{2}$, have relative magnitudes which are opposite to those observed experimentally. Notwithstanding the known difficulties in DFT-calculated EPR parameters matching with those from experiments, the relatively large differences seen between the experimental and calculated EPR parameters for species 1 are a recurring theme in DFT calculations on AA10 LPMO active sites in their $\mathrm{Cu}$ (II) resting states, even with careful selection of the basis sets and functionals. ${ }^{26}$ As such, while the optimised structure of 1 matches well that of the experiment and is likely a good representation of the actual structure, caution must be applied in interpreting the calculated EPR data for species 1, where the reasons for the discrepancies between theoretical and experimental results remain unclear. This situation is in contrast to the calculations of the EPR parameters for species 2 and 3, which give a somewhat closer match to the experimental data (see below).

Following the ligand field analysis above, species 2 was initially modelled by removing the proton shared between the water and glutamate, and by transferring the proton attached to the second water ligand to the $-\mathrm{NH}_{2}$ group (representing an overall removal of a single proton from species 1 , as per the experimental

Table 2 Calculated spin Hamiltonian parameters of the $\mathrm{pH}$ dependent species. The $x$ axis of the calculated $g$ tensor lies along the His-Cu-His direction

\begin{tabular}{|c|c|c|c|c|c|c|}
\hline \multirow[b]{2}{*}{ Species } & \multicolumn{3}{|c|}{$g$ values } & \multicolumn{3}{|c|}{$\begin{array}{l}\text { Hyperfine coupling constants/ } \\
\mathrm{MHz}\end{array}$} \\
\hline & $g_{x}$ & $g_{y}$ & $g_{z}$ & $\left|A_{x}\right|$ & $\left|A_{y}\right|$ & $A_{z}$ \\
\hline 1 & 2.049 & 2.081 & 2.216 & 110 & 29 & -598 \\
\hline 2 & 2.070 & 2.079 & 2.244 & 94 & 3 & -582 \\
\hline 3 & 2.037 & 2.070 & 2.188 & 15 & 140 & -496 \\
\hline
\end{tabular}


findings). Upon optimisation, the angle between the hydroxide ligands, $\angle \mathrm{O}-\mathrm{Cu}-$ $\mathrm{O}$, increased from $\mathrm{ca} .90^{\circ}$ to $157^{\circ}$. The divergence of the hydroxide ligands was also accompanied by the expected decoordination of the now protonated $-\mathrm{NH}_{3}{ }^{+}$ group from the metal and a rotation of the $\mathrm{d}\left(x^{2}-y^{2}\right)$ SOMO by $c a .45^{\circ}$ (Fig. 6), such that the equatorial plane was now defined by the two hydroxides and the nitrogen atoms of two histidine ligands, thus completing the $\mathrm{CuN}_{2} \mathrm{O}_{2}$ coordination geometry expected from the ligand field analysis. The calculated EPR parameters (Table 2) for species 2 reflect the experimental data in that $g_{x}$ and $g_{y}$ are closer in values, and that the value of $g_{z}$ is $c a$. 2.24.

Species 3 was modelled as a $\mathrm{Cu}(\mathrm{II})$-azanide species formed by the expulsion of water from species 2 , followed by the further removal of an $-\mathrm{NH}_{2}$ proton, resulting in a short $\mathrm{Cu}-\mathrm{NH}$ bond of $1.94 \mathrm{~A}$ (full computational details can be found in the $\mathrm{ESI} \dagger$ ). The optimised geometry is best described as $\mathrm{CuN}_{3} \mathrm{O}$ planar, albeit distorted ( $\angle \mathrm{HN}-\mathrm{Cu}-\mathrm{O} \sim 160^{\circ}$ ). This distortion away from planar has been previously reported for four-coordinate LPMO structures when modelled by DFT. ${ }^{15}$ The calculated EPR parameters for species 3 match well with those from experiments,

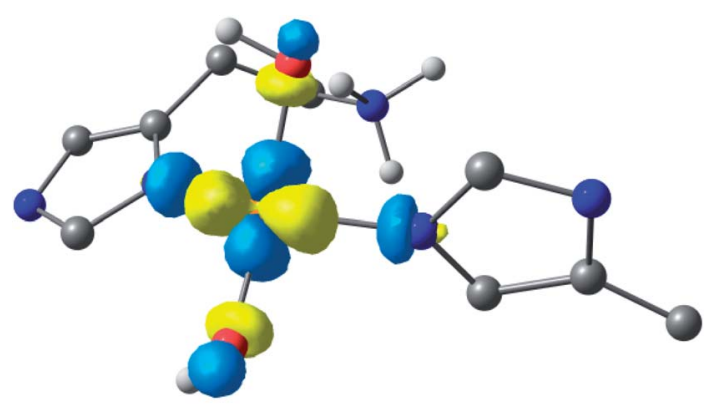

Fig. 6 Hypothetical $d\left(x^{2}-y^{2}\right)$ dominated SOMO of species 2 showing that the orbital plane has rotated (the colours denote the orbital phases).

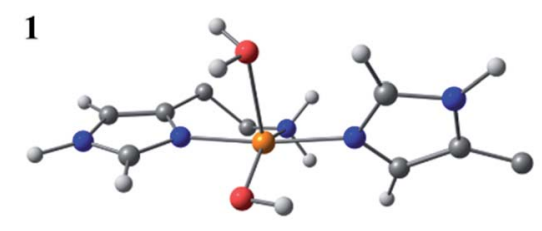

2
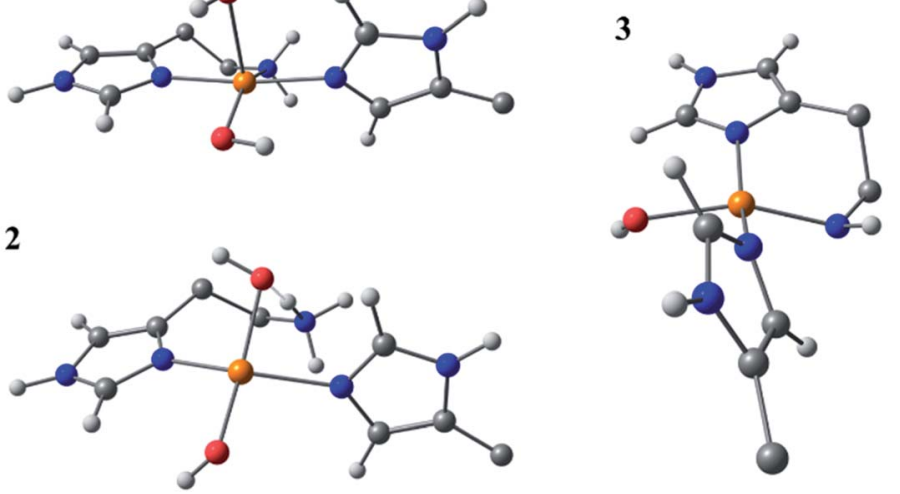

Fig. 7 DFT optimised geometries of species 1, 2 and 3. The models are truncated, and certain atoms are hidden for clarity. 
most notably in the $g_{3, z}$ value of 2.18. Also, from a spectroscopic perspective, Species 3 exhibits a semi-intense UV/visible absorption band centred at $520 \mathrm{~nm}(\varepsilon$ $\approx 2500 \mathrm{M}^{-1} \mathrm{~cm}^{-1}$ ). This band is proposed to arise from a LMCT transition from the proposed azanide group to the $\mathrm{Cu}$, which is corroborated with the TD-DFT calculations (ESI $\dagger$ ). Both the $\mathrm{d}-\mathrm{d}$ and LMCT transition energies appear to be significantly blue-shifted with respect to the experimental transitions. Exact transition energies are known to carry significant error when calculated in this way for open shell systems. Nevertheless, these calculations reveal that an intense absorption band is expected for the $\mathrm{Cu}(\mathrm{II})$-azanide complex proposed as species 3 and its energy is predicted to be positioned between the $\pi-\pi^{*}$ and the $\mathrm{d}-\mathrm{d}$ transitions. The three optimised structures for species 1, 2 and 3 are shown in Fig. 7.

\section{Conclusions}

Herein, we establish three discrete protonation states for an AA10 LPMO within the $\mathrm{pH}$ range of 6.5 to 12.5 , two of which are biologically relevant and may be important in the context of the LPMO mechanism. The first species exists at acidic-neutral $\mathrm{pH}$ and is believed to be consistent with a 5-coordinate $\left(\mathrm{N}_{3} \mathrm{O}_{2}\right)$, in keeping with the current understanding of the chitin-active AA10 coordination sphere. A second species is formed by deprotonating the ligating water molecule $\left(\mathrm{p} K_{\mathrm{a}} 8.7\right)$; yielding a near-axial EPR spectral envelope $\left(g_{1}=2.044, g_{2}=2.069\right.$ and $\left.g_{3}=2.233\right)$. We hypothesise that this species exists as a $\mathrm{N}_{2} \mathrm{O}_{2}, 4$-coordinate ligand field with two hydroxide ligands and an elongated/decoordinated $-\mathrm{R}^{-\mathrm{NH}_{3}}{ }^{+}$ following proton transfer from the coordinating hydroxide to the amino terminus. This gives rise to a rotated SOMO which is no longer defined by the chelating histidine brace. The third species formed at a high $\mathrm{pH}\left(\mathrm{p} K_{\mathrm{a}} \sim 11.5\right)$ is proposed to exist as a 4-coordinate, $\mathrm{N}_{3} \mathrm{O}$ complex, whereby species 2 has lost a water molecule (from the interaction of an $\mathrm{OH}^{-}$and $\mathrm{NH}_{3}{ }^{+}$) and the $-\mathrm{NH}_{2}$ group has been deprotonated to form a $\mathrm{Cu}(\mathrm{II})-\mathrm{NH}$ azanide complex. The high $\mathrm{pH}$ at which this species becomes accessible is outside of that which is biologically relevant and, as such, is unlikely to be pertinent in catalysis.

\section{Conflicts of interest}

There are no conflicts to declare.

\section{Acknowledgements}

We acknowledge the University of York for the support of PJL's PhD studentship. We thank Z. Forsberg, G. Courtade, V. G. H. Eijsink and F. L. Aachmann for providing the clone/cell colonies and purification protocol for the BlAA10 enzyme. GJD thanks the Royal Society for the Ken Murray Research Professorship.

\section{Notes and references}

1 G. Vaaje-Kolstad, B. Westereng, S. J. Horn, Z. Liu, H. Zhai, M. Sørlie and V. G. H. Eijsink, Science, 2010, 330, 219-222.

2 R. J. Quinlan, M. D. Sweeney, L. Lo Leggio, H. Otten, J.-C. N. Poulsen, K. S. Johansen, K. B. R. M. Krogh, C. I. Jørgensen, M. Tovborg, 
A. Anthonsen, T. Tryfona, C. P. Walter, P. Dupree, F. Xu, G. J. Davies and P. H. Walton, Proc. Natl. Acad. Sci. U. S. A., 2011, 108, 15079-15084.

3 C. M. Phillips, W. T. Beeson, J. H. Cate and M. A. Marletta, ACS Chem. Biol., 2011, 6, 1399-1406.

4 L. Ciano, G. J. Davies, W. B. Tolman and P. H. Walton, Nat. Catal., 2018, 1, 571577.

5 G. R. Hemsworth, B. Henrissat, G. J. Davies and P. H. Walton, Nat. Chem. Biol., 2014, 10, 122-126.

6 V. V. Vu, W. T. Beeson, E. A. Span, E. R. Farquhar and M. A. Marletta, Proc. Natl. Acad. Sci. U. S. A., 2014, 111, 13822-13827.

7 M. Couturier, S. Ladevèze, G. Sulzenbacher, L. Ciano, M. Fanuel, C. Moreau, A. Villares, B. Cathala, F. Chaspoul, K. E. Frandsen, A. Labourel, I. HerpoëlGimbert, S. Grisel, M. Haon, N. Lenfant, H. Rogniaux, D. Ropartz, G. J. Davies, M.-N. Rosso, P. H. Walton, B. Henrissat and J.-G. Berrin, Nat. Chem. Biol., 2018, 14, 306.

8 F. Sabbadin, G. R. Hemsworth, L. Ciano, B. Henrissat, P. Dupree, T. Tryfona, R. D. S. Marques, S. T. Sweeney, K. Besser, L. Elias, G. Pesante, Y. Li, A. A. Dowle, R. Bates, L. D. Gomez, R. Simister, G. J. Davies, P. H. Walton, N. C. Bruce and S. J. McQueen-Mason, Nat. Commun., 2018, 9, 756.

9 C. Filiatrault-Chastel, D. Navarro, M. Haon, S. Grisel, I. Herpoël-Gimbert, D. Chevret, M. Fanuel, B. Henrissat, S. Heiss-Blanquet, A. Margeot and J.-G. Berrin, Biotechnol. Biofuels, 2019, 12, 55.

10 F. Sabbadin, S. Urresti, B. Henrissat, A. O. Avrova, L. R. J. Welsh, P. Lindley, M. Csukai, J. N. Squires, P. H. Walton, G. J. Davies, N. C. Bruce, S. C. Whisson and S. J. McQueen Mason, Science, 2021, 373, 774-779.

11 G. R. Hemsworth, E. J. Taylor, R. Q. Kim, R. C. Gregory, S. J. Lewis, J. P. Turkenburg, A. J. Parkin, G. J. Davies and P. H. Walton, J. Am. Chem. Soc., 2013, 135, 6069-6077.

12 F. L. Aachmann, M. Sørlie, G. Skjåk-Bræk, V. G. H. Eijsink and G. VaajeKolstad, Proc. Natl. Acad. Sci. U. S. A., 2012, 109, 18779-18784.

13 N. Gagnon and W. B. Tolman, Acc. Chem. Res., 2015, 48, 2126-2131.

14 J.-P. Bacik, S. Mekasha, Z. Forsberg, A. Y. Kovalevsky, G. Vaaje-Kolstad, V. G. H. Eijsink, J. C. Nix, L. Coates, M. J. Cuneo, C. J. Unkefer and J. C. H. Chen, Biochemistry, 2017, 56, 2529-2532.

15 G. Courtade, L. Ciano, A. Paradisi, P. J. Lindley, Z. Forsberg, M. Sørlie, R. Wimmer, G. J. Davies, V. G. H. Eijsink, P. H. Walton and F. L. Aachmann, Proc. Natl. Acad. Sci. U. S. A., 2020, 117, 19178-19189.

16 G. Courtade, S. B. Le, G. I. Sætrom, T. Brautaset and F. L. Aachmann, Carbohydr. Res., 2017, 448, 212-219.

17 G. R. Hemsworth, L. Ciano, G. J. Davies and P. H. Walton, in Methods Enzymol., ed. F. Armstrong, Academic Press, 2018, vol. 613, pp. 63-90.

18 B. Bissaro, I. Isaksen, G. Vaaje-Kolstad, V. G. H. Eijsink and Å. K. Røhr, Biochemistry, 2018, 57, 1893-1906.

19 M. A. Hitchman and R. L. Belford, Inorg. Chem., 1969, 8, 958-965.

20 R. C. Gregory, G. R. Hemsworth, J. P. Turkenburg, S. J. Hart, P. H. Walton and G. J. Davies, Dalton Trans., 2016, 45, 16904-16912.

21 K. E. H. Frandsen, T. J. Simmons, P. Dupree, J.-C. N. Poulsen, G. R. Hemsworth, L. Ciano, E. M. Johnston, M. Tovborg, K. S. Johansen, P. von Freiesleben, L. Marmuse, S. Fort, S. Cottaz, H. Driguez, B. Henrissat, 
N. Lenfant, F. Tuna, A. Baldansuren, G. J. Davies, L. Lo Leggio and P. H. Walton, Nat. Chem. Biol., 2016, 12, 298.

22 J. Peisach and W. E. Blumberg, Arch. Biochem. Biophys., 1974, 165, 691-708.

23 B. Bissaro, B. Streit, I. Isaksen, V. G. H. Eijsink, G. T. Beckham, J. L. DuBois and A. K. Røhr, Proc. Natl. Acad. Sci. U. S. A., 2020, 117, 1504.

24 A. Paradisi, M. J. Steward, P. Lindley, G. J. Davies and P. H. Walton, in Reference Module in Chemistry, Molecular Sciences and Chemical Engineering, Elsevier, 2020, DOI: 10.1016/B978-0-12-409547-2.14928-5.

25 M. J. Harms, C. A. Castañeda, J. L. Schlessman, G. R. Sue, D. G. Isom, B. R. Cannon and B. E. García-Moreno, J. Mol. Biol., 2009, 389, 34-47.

26 Y. A. Theibich, S. P. A. Sauer, L. L. Leggio and E. D. Hedegård, Comput. Struct. Biotechnol. J., 2021, 19, 555-567.

27 S. Stoll and A. Schweiger, J. Magn. Reson., 2006, 178, 42-55. 